\title{
COMPARISON OF MULTI-SOURCE DATA, INTEGRATED SURVEY FOR COMPLEX ARCHITECTURE DOCUMENTATION
}

\author{
F. Rinaudo ${ }^{1}$, V. Scolamiero ${ }^{1}$ \\ ${ }^{1}$ DAD, Department of Architecture and Design, Politecnico di Torino, Viale Mattioli 39, 10125 Torino \\ (fulvio.rinaudo, vittorio.scolamiero)@polito.it
}

KEY WORDS: Metric Documentation, MMS, LiDAR, UAV, Multisensor, Data Integration, Accuracy.

\begin{abstract}
:
The metric documentation of architectural complexes requires today the use of several integrated survey methodologies. This need is an answer to the morphology of the object such as dimension, geometry, inaccessible areas and urban context. These properties inhibit the use of single surveying techniques and force the integration of Geomatics tools. In addition, the metric documentation of Cultural heritage objects not always requires uniform accuracy and resolution, therefore the integration of different surveying methodologies and techniques become the only effective solution both from a technical and economic point of view. The integration, that is today adopted as normal strategy, allows also the better understanding of the benefits which can arise to speed up the metric documentation of Cultural Heritage objects and the benefits that each of the possible surveying techniques can have thanks to the integration of the different potentialities. This study starting from an integrated survey, performed whit a combined use of Mobile Mapping System (MMS), Unmanned Aerial Vehicles (UAV) and Terrestrial Laser Scanner (TLS) and show the results of the comparisons between the possible achievable accuracies by using a correct integration between the different used technologies and the ones achievable by using the same techniques as independent tools.

The case study is the architectural complex of the Ducal Palace in Gubbio (Italy), located upstream of the most important town square facing the cathedral in a very complex but realistic urban context.
\end{abstract}

\section{INTRODUCTION}

The metric survey of complex architectural structures always requires the integration of different geomatics techniques.

The metric survey is never an end in itself but is always carried out in support of specific analyses and planning of conservation and restoration interventions as well as the planning of management interventions.

Each of these actions requires metric surveys of a different nature and metric and descriptive content. This differentiation may also be necessary in different parts of the same complex and therefore the use of integrations of more than one metric survey technique is especially acceptable from an economic point of view.

Another reason that justifies the current trend towards the integration of different measurement techniques, lies in the fact that each technique (aerial and terrestrial photogrammetry, laser scanner, SLAM, etc.) has limits both of achievable accuracy and of possible degree of detail.

Finally, as a third reason that justifies the now commonly accepted recourse to the integration of different metric survey techniques in one or the same complex, we can consider the limits of applicability of each of the techniques due to both environmental limits (necessary spaces, lighting, etc.) and limits in the times of accessibility possible in the complex itself.

Integration, first presented as a contingent necessity due to the limitations of the different techniques or to the properties to which the metric survey must answer in different situations, must not however be seen as a limit or even a complication to which the surveyor must submit.

The evolution of geomatics techniques has shown in the past how, from the integration of different technologies, undoubted advantages can often be obtained for the technologies themselves.

In the 90 s of the last century the integration between laser scanner techniques and digital photogrammetry brought undoubted advantages to both techniques. The interpretation of point clouds obtained with laser scanning techniques would not have been possible as easily as we can appreciate today without the use of oriented digital images. At the same time, the production of orthophotos and the search for homologous points on stereoscopic images has been greatly facilitated by the ease of having shape models (DSM) quickly and with more than acceptable accuracy in all applications.

Today the techniques that are most used in an integrated approach in the survey of complex architectures are digital photogrammetry (both aerial and terrestrial), terrestrial and aerial scanning techniques and, recently, also SLAM (Simultaneous Localization And Mapping) based techniques. The introduction of this last technology in the metric survey has been facilitated by the development of increasingly performing and easy-to-use equipment during the acquisition of primary data.

It is now an incontrovertible fact that the SLAM based instruments allows rapid acquisition times of point clouds in spaces where photogrammetric and laser scanner techniques would find many difficulties both in terms of feasibility and in terms of primary data acquisition speed.

The main purpose of the work described below is to evaluate the advantages that the SLAM technique can obtain from an integration with photogrammetric and laser scanning techniques in terms of accuracy of the measured data.

However, it is also known that the levels of accuracy that can be achieved with SLAM techniques are in many cases lower than those that the other two techniques mentioned above can guarantee.

Some researchers published some interesting results about the different accuracies reached by using automatic digital photogrammetric tools compared with laser scanner performances (Torres et al., 2014) by showing that, at that time, the existing gap between laser scanner and automatic digital 
photogrammetry to produce DSM (Digital Surface Model) was recovered. Using a cloud-to-cloud comparison they showed discrepancies lower than $3 \mathrm{~cm}$ between the two point clouds. One of the first comparisons between laser scanner, photogrammetry and SLAM systems were presented some years later (Chiabrando et al., 2016) more concentrated on the density of the different obtainable point clouds and a possible integration of them into a unique set of primary data useful to speed up the acquisition in dangerous area. They showed that the integration of the two point clouds could give enough information to generate profiles useful to assess the structure stability of ruined building after an earthquake by reducing the risk for surveyor thanks to the speed of acquisition of the SLAM based instruments.

Some of the first results in assessing the metric performances of SLAM systems were obtained by using a cloud-to-cloud comparison of pint clouds obtained by using terrestrial laser scanners and SLAM systems (Masiero et al., 2017; Malinverni et al., 2018). Discrepancies of about $30 \div 40 \mathrm{~cm}$ were established as maximum metric differences of the two measuring systems.

The possibility to register SLAM based point clouds by using the more precise information coming out form laser scanner point clouds showed a great increasing of the accuracy of SLAM results. By using a set of distances measured on the surveyed object and the corresponding on the point clouds obtained by using a SLAM system showed discrepancies less than $1 \mathrm{~cm}$ (Russhakim et al., 2019).

The results that will be presented in the next paragraphs add new experiences in managing a full integration of the three above mentioned technologies and the increase of accuracy that this approach could give to the metric quality of SLAM based point clouds.

The analysed data were acquired to perform the survey of the Palazzo Ducale in Gubbio (Italy) a morphologically complex building were the integration of laser scanner, photogrammetry and SLAM systems was a must by considering the dimension of the internal connections between the different floors and the accessibility limitation due to the surrounding buildings (Patrucco et al., 2019).

\section{THE PALAZZO DUCALE IN GUBBIO (ITALY)}

The architectural complex of the Palazzo Ducale, located upstream of the most important town square, faces the cathedral of Gubbio (province of Perugia) in a very complex urban context (see Figure 1).

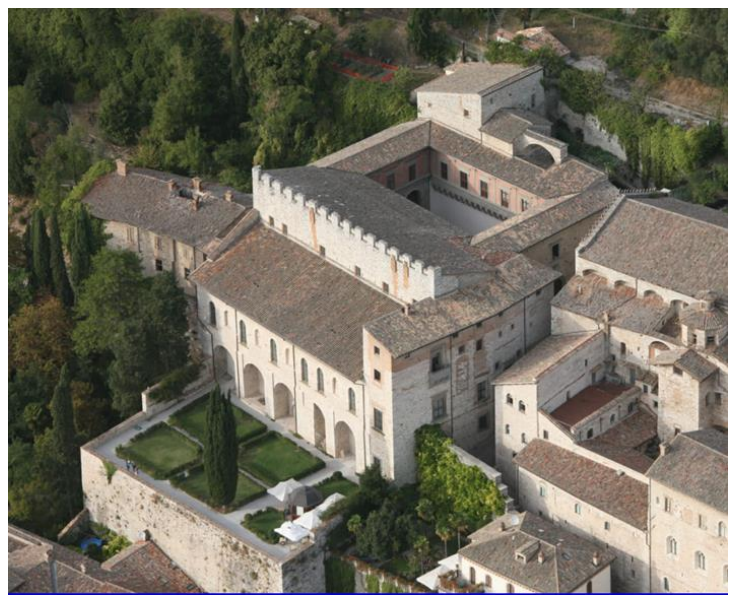

Figure 1. Aerial view of the Palazzo Ducale
The palace was built by the will of the Duke of Urbino Federico da Montefeltro, on a pre-existing medieval buildings. The complex, probably designed by the architect Francesco di Giorgio Martini, is divided into two buildings joined by a central courtyard, and was certainly built at the end of $\mathrm{XV}$ century, when the pre-existing buildings, owned by the municipality of Gubbio, were donated in 1480 to the Montefeltro family.

Therefore, the complex represents the result of an evolutionary process consolidated over time that describes a unique historical testimony.

As it could be observed today, it is made up of multiple historical stratifications. Originally the first municipal building, a tower and a guard room were located at the Northern part of the current complex. The guard's palace was later built along the side facing the valley and the "platea communis" was located in the centre of these complex. Below this space there are two underground levels characterized by pre-existing walls dating back to $\mathrm{X}$ and XIV century. Today the palace hosts the Palazzo Ducale museum.

\section{SURVEY STRATEGIES}

The survey methodology used in this work tries to favour the integrated use of different sensor to obtain a dataset as complete as possible by considering the specific needs of the future users of the metric survey.

The choice of where and when different technologies can be used strongly depends on the requirement by the end user of the resulting 3D model. In the example used in this work, some parts of the complex do not require a high metric accuracy because recently restored and full equipped with technological devices, while other part require (inner spaces, roofs, facades) accuracies at 1:100 scale (e.g. $\pm 2 \mathrm{~cm}$ ) because they are used for temporary events and therefore need a continuous re-planning of interior spaces and technological installations (inner spaces) or are under restoration and continuous rehabilitation due to deteriorations problems.

Therefore, a LiDAR (Light Detection and Ranging) survey has been executed in all accessible outdoor and indoor spaces that require the maximum accuracy.

Automatic digital photogrammetry, by using images acquired by UAV, was considered to survey the inaccessible part of the complex, like roofs and the main facades of the building.

Finally, the Mobile mapping system, based on a SLAM (Simultaneous Localization and Mapping) algorithm, was used to survey spaces where lower accuracy can be accepted. Figure 2 shows the different parts of the complex acquired by each of the above mentioned techniques.

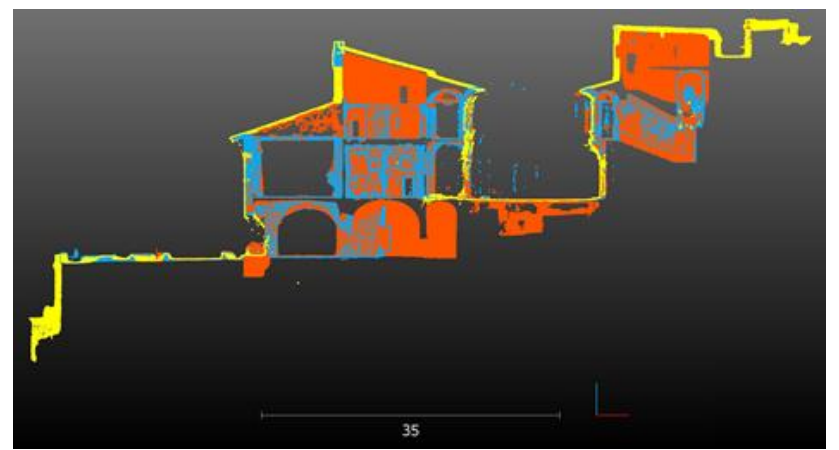

Figure 2. Primary data acquisition: photogrammetric images (yellow), TLS point clouds (red), and SLAM point clouds (blue) 


\subsection{Used instruments and recorded primary data}

The general overview of the acquired primary data is summarized in Table 1. Each survey techniques requires different procedures for data acquisition and each technique is characterized by different precision and resolution.

\begin{tabular}{|c|c|c|}
\hline Systems & Sensor & Dataset \\
\hline UAV & DJI Mavic Pro & 1658 images \\
\hline TLS & FARO Focus $^{3 \mathrm{D}}$ S120 & 78 scans \\
\hline TLS & FARO Focus $^{3 \mathrm{D}}$ X330 & 64 scans \\
\hline MMS & GeoSLAM ZEB Revo RT & 12 scans \\
\hline TS & Geomax manual TS & 45 vertices, 412 targets \\
\hline
\end{tabular}

Table 1. General overview of sensor employed, and data collected

The UAV image acquisition has been carried out using a drone DJI Mavic Pro, equipped whit a DJI FC220 camera. Six flights (see Table 2) have been executed to collected data of the selected outer area; only the first three flights were acquired whit a pre-planned mode, while the last three flights were acquired in manual mode to obtain more appropriate acquisition and to avoid the lack of GNSS connection due to the urban complexity around the complex.

\begin{tabular}{|c|c|c|c|}
\hline Flight & \# images & Flight & Taken distance \\
\hline 1 & 261 & PLANNED & $\approx 68 \mathrm{~m}$ \\
\hline 2 & 234 & PLANNED & $\approx 68 \mathrm{~m}$ \\
\hline 3 & 32 & PLANNED & $\approx 68 \mathrm{~m}$ \\
\hline 4 & 366 & MANUAL & $\approx 16 \mathrm{~m}$ \\
\hline 5 & 316 & MANUAL & $\approx 10 \mathrm{~m}$ \\
\hline 6 & 449 & MANUAL & $\approx 10 \mathrm{~m}$ \\
\hline
\end{tabular}

Table 2. Detail of UAV dataset

The data sets were acquired with a nadir and oblique camera configuration. The first three flights have been integrated together in a single photogrammetric project to obtain a complete aerial model of the area (fig. 3).

The LiDAR survey was performed whit a ToF TLS Faro Focus $^{3 \mathrm{D}}$ S120 and a Faro Focus ${ }^{3 \mathrm{D}}$ X330, the error in distance measurement of these system is $\pm 2 \mathrm{~mm}$; 142 scans were acquired to cover the test area, and all of them have been acquired whit a quality $4 \mathrm{x}$ and a resolution of $1 / 5$. These values correspond to 1 point every $8 \mathrm{~mm}$ at a distance of about $10 \mathrm{~m}$ (see Table 3 and Figure 4).

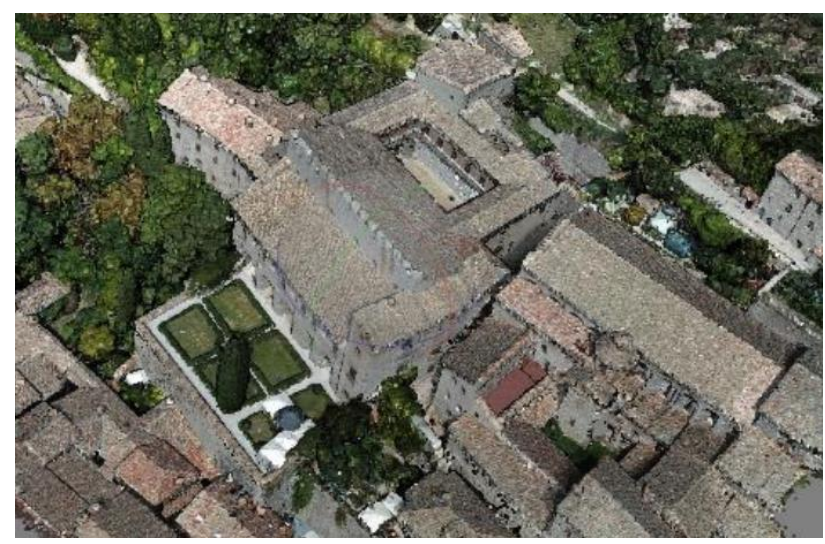

Figure 3. Photogrammetric point cloud

\begin{tabular}{|c|c|c|c|}
\hline Block & \# scans & $\begin{array}{c}\text { Acquisition time } \\
{[\mathbf{m i n}]}\end{array}$ & \# points \\
\hline 1 & 10 & 85,4 & 261.249 .664 \\
\hline 2 & 11 & 93,4 & 259.340 .637 \\
\hline 3 & 13 & 111,5 & 285.393 .037 \\
\hline 4 & 8 & 68,3 & 195.121 .169 \\
\hline 5 & 5 & 42,7 & 103.175 .709 \\
\hline 6 & 15 & 128,1 & 386.310 .833 \\
\hline 7 & 3 & 25,6 & 83.847 .583 \\
\hline 8 & 22 & 188,3 & 309.064 .477 \\
\hline 9 & 5 & 42,7 & 89.278 .854 \\
\hline 10 & 13 & 111,7 & 121.448 .450 \\
\hline 11 & 10 & 68,3 & 359.773 .558 \\
\hline 12 & 22 & 188,3 & 613.107 .688 \\
\hline 13 & 5 & 42,7 & 140.525 .202 \\
\hline
\end{tabular}

Table 3. TLS acquired dataset

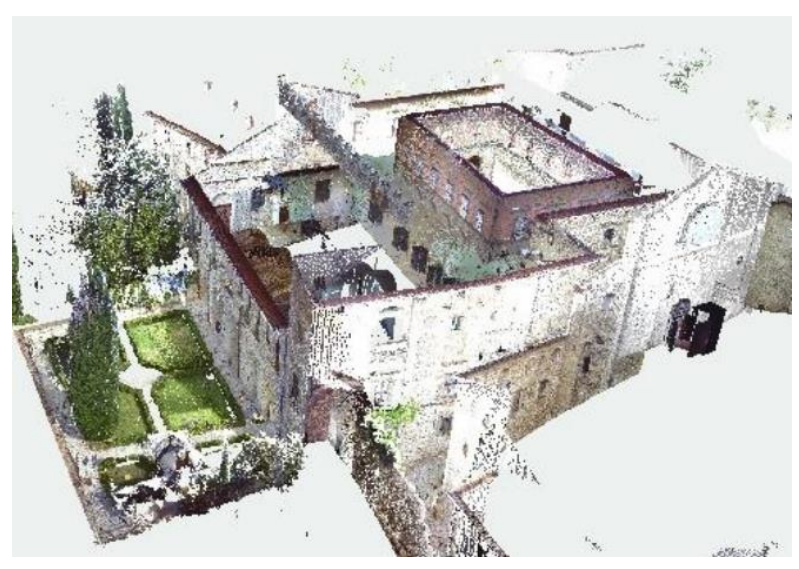

Figure 4. TLS point cloud

The Mobile Mapping System used to survey the test area was the ZEB Revo Real Time (RT). This instrument is an MMS based on a SLAM algorithm and is equipped whit a handheld laser scanner and a RGB camera. ZEB Revo Real time RT represent a rapid mapping solution: the survey of the entire architectural complex required only about 125 minutes. This system has been adopted to survey the most difficult areas of the building to reach through the use of TLS and characterized by little lighting so as not to allow perfect photogrammetric acquisition, such as the underground rooms of the buildings.

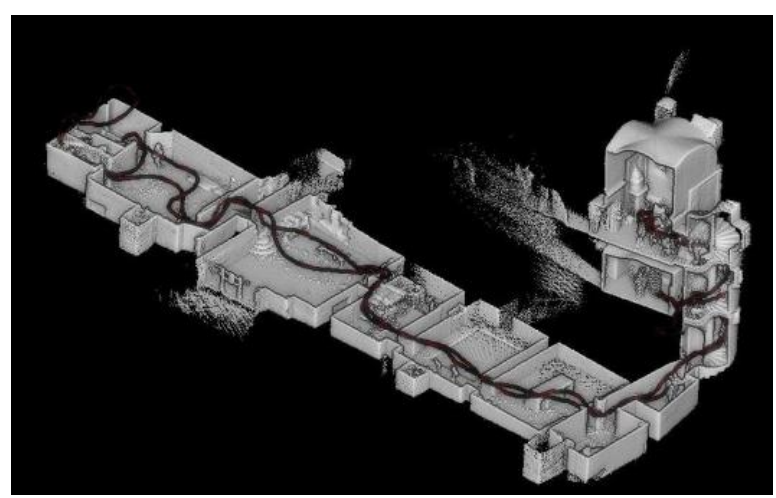

Figure 5. MMS point cloud. The paths are shown by dark line 


\begin{tabular}{|c|c|c|}
\hline \# scan & Acquisition time [min] & \# points \\
\hline 1 & 7,15 & 15.302 .472 \\
\hline 2 & 11,5 & 23.851 .663 \\
\hline 3 & 8,6 & 18.420 .264 \\
\hline 4 & 12 & 24.918 .629 \\
\hline 5 & 12,1 & 28.176 .481 \\
\hline 6 & 9,2 & 20.162 .581 \\
\hline 7 & 11,3 & 22.349 .861 \\
\hline 8 & 9,2 & 19.636 .188 \\
\hline 9 & 10,1 & 22.173 .975 \\
\hline 10 & 12,2 & 30.639 .964 \\
\hline 11 & 12,1 & 24.225 .364 \\
\hline 12 & 9,3 & 20.050 .087 \\
\hline
\end{tabular}

Table 4. MMS datasets

The scanning procedure to be followed by MMS systems is very important because it inevitably affects the quality of the data; consequently, the adopted acquisition method was the execution of the loops, that is the closed path in the same starting position (see Figure 5). This scanning strategy facilitates the SLAM based software in $3 \mathrm{D}$ reconstruction by minimizing errors along the trajectory and increasing the rigidity of the system. Table 4 shows the summary of the data acquired by using the MMS.

\subsection{MMS accuracy assessment}

Due the high speed of acquisition of the SLAM based system, the entire building was surveyed by using this technique to allow a comparison of different achievable accuracies by considering different possible treatment of SLAM data.

As usual, the coordinate system, where all the collected data are referred to, has been fixed by means of traditional topographic methods.

To allow the accuracy assessment, some pre-signalized points have been placed and surveyed by using a total station with redundant survey methods from the different vertex of the control network to be able to estimate their precision and accuracy with the least square adjustment approach.

For those points a precision of about $2 \mathrm{~mm}$ was reached: this allow one to assume those points as more precise that the ones obtained by using automatic digital photogrammetry and TLS, and therefore able to allow a rigorous assessment of the different accuracies achieved by MMS data.

Table 5 shows the discrepancies between the coordinates of the check points (CPs) estimated by using Total Station measurements and the ones obtained from the point clouds generated by terrestrial laser scanner (TLS), automatic digital photogrammetry (ADP), and the GeoSLAM ZEB Revo RT point clouds without any elaboration after the first adjustment (MMS1).

\begin{tabular}{|c|c|c|c|c|c|c|c|c|c|c|c|c|}
\hline \multirow{2}{*}{$\#$} & \multicolumn{3}{|c|}{ TS } & \multicolumn{3}{|c|}{ TLS - TS } & \multicolumn{3}{|c|}{ ADP - TS } & \multicolumn{3}{|c|}{ MMS1 - TS } \\
\hline & $\mathbf{X}[\mathrm{m}]$ & $\mathbf{Y}[\mathrm{m}]$ & $\mathbf{Z}[\mathbf{m}]$ & $\Delta \mathbf{X}[\mathbf{m}]$ & $\Delta \mathrm{Y}[\mathrm{m}]$ & $\Delta \mathbf{Z}[\mathrm{m}]$ & $\Delta \mathbf{X}[\mathbf{m}]$ & $\Delta \mathrm{Y}[\mathrm{m}]$ & $\Delta \mathbf{Z}[\mathrm{m}]$ & $\Delta \mathbf{X}[\mathbf{m}]$ & $\Delta \mathrm{Y}[\mathrm{m}]$ & $\Delta \mathbf{Z}[\mathrm{m}]$ \\
\hline 1 & 66,321 & 112,445 & 92,494 & $-0,001$ & 0,008 & 0,023 & 0,001 & $-0,002$ & 0,019 & $-0,250$ & $-0,007$ & 0,192 \\
\hline 2 & 69,154 & 113,965 & 91,214 & 0,001 & 0,003 & 0,006 & $-0,001$ & 0,011 & 0,005 & $-0,197$ & 0,058 & 0,193 \\
\hline 3 & 68,009 & 119,291 & 91,38 & $-0,003$ & $-0,007$ & $-0,001$ & $-0,003$ & 0,005 & 0,004 & $-0,282$ & 0,089 & 0,319 \\
\hline 4 & 69,019 & 123,72 & 92,848 & $-0,010$ & $-0,002$ & $-0,004$ & $-0,001$ & $-0,010$ & 0,002 & $-0,297$ & 0,102 & 0,315 \\
\hline 5 & 72,118 & 127,687 & 92,94 & $-0,009$ & $-0,009$ & 0,009 & $-0,002$ & $-0,020$ & 0,000 & 0,448 & $-0,005$ & $-0,174$ \\
\hline 6 & 71,901 & 135,971 & 91,422 & $-0,012$ & 0,009 & $-0,014$ & 0,015 & 0,009 & $-0,021$ & $-0,243$ & 0,075 & 0,424 \\
\hline 7 & 74,812 & 138,475 & 92,978 & $-0,005$ & $-0,012$ & 0,002 & $-0,009$ & $-0,009$ & $-0,015$ & $-0,419$ & 0,026 & 0,131 \\
\hline 8 & 75,398 & 140,801 & 91,102 & 0,000 & $-0,008$ & $-0,004$ & $-0,028$ & $-0,016$ & $-0,005$ & $-0,138$ & $-0,005$ & 0,007 \\
\hline 9 & 116,126 & 107,756 & 103,178 & $-0,004$ & 0,004 & $-0,016$ & $-0,014$ & $-0,015$ & 0,001 & $-0,016$ & $-0,292$ & 0,186 \\
\hline 10 & 110,296 & 108,522 & 100,203 & $-0,006$ & $-0,014$ & $-0,041$ & $-0,015$ & $-0,022$ & 0,006 & $-0,014$ & $-0,160$ & 0,105 \\
\hline 11 & 104,437 & 109,143 & 100,18 & $-0,012$ & $-0,002$ & $-0,011$ & 0,008 & 0,005 & 0,001 & $-0,026$ & $-0,077$ & 0,050 \\
\hline 12 & 101,494 & 109,517 & 98,293 & $-0,009$ & $-0,007$ & $-0,035$ & 0,008 & $-0,002$ & $-0,017$ & 0,016 & $-0,348$ & 0,227 \\
\hline 13 & 96,704 & 110,137 & 100,131 & $-0,005$ & $-0,009$ & $-0,022$ & $-0,004$ & 0,009 & 0,001 & $-0,024$ & $-0,001$ & 0,008 \\
\hline 14 & 85,784 & 151,59 & 98,415 & 0,005 & 0,013 & $-0,004$ & 0,016 & 0,011 & 0,001 & $-0,019$ & 0,057 & 0,018 \\
\hline 15 & 84,945 & 147,204 & 99,17 & $-0,002$ & $-0,007$ & 0,003 & 0,005 & 0,001 & 0,001 & $-0,032$ & 0,042 & 0,009 \\
\hline 16 & 80,795 & 146,994 & 97,851 & $-0,007$ & $-0,003$ & 0,000 & $-0,003$ & $-0,003$ & $-0,002$ & $-0,019$ & 0,040 & 0,045 \\
\hline \multicolumn{4}{|c|}{ Mean [m] } & $-0,005$ & $-0,003$ & $-0,007$ & $-0,002$ & $-0,003$ & $-0,001$ & $-0,094$ & $-0,025$ & 0,128 \\
\hline \multicolumn{4}{|c|}{ St. Dev. [m] } & 0,005 & $\mathbf{0 , 0 0 8}$ & 0,016 & 0,011 & 0,011 & 0,010 & 0,197 & 0,132 & 0,151 \\
\hline
\end{tabular}

Table 5. Residuals of 3D coordinates on a set of signalized points

A second comparison has been done by using a set of distances measured on well recognizable points in the different point clouds generated by Automatic Digital Photogrammetry, Terrestrial Laser Scanning and ZEB Revo Real Time (RT): for the last one on the original point clouds of each ring the radiometry has been re-projected by using the radiometry of the images used for the photogrammetric survey. Table 6 shows the obtained discrepancies.

By analysing the means and standard deviations of the obtained residuals shown in Tables 5 and 6 it is possible to observe, as it is well known, the almost similar accuracy of Digital Automatic Photogrammetry and Terrestrial Laser Scanning techniques and 
a big gap of the data acquired by using the SLAM based system without any further arrangements.

\begin{tabular}{|c|c|c|c|}
\hline \# & ADP [m] & TLS-ADP [m] & MM1-ADP[m] \\
\hline 1 & 3,473 & $-0,008$ & 0,059 \\
\hline 2 & 7,147 & $-0,019$ & 0,058 \\
\hline 3 & 11,590 & $-0,004$ & 0,108 \\
\hline 4 & 16,295 & $-0,001$ & 0,275 \\
\hline 5 & 24,218 & $-0,015$ & 0,072 \\
\hline 6 & 27,374 & $-0,010$ & $-0,011$ \\
\hline 7 & 29,785 & 0,007 & 0,066 \\
\hline 8 & 5,445 & $-0,004$ & 0,059 \\
\hline 9 & 9,871 & 0,015 & 0,087 \\
\hline 10 & 14,113 & 0,017 & 0,080 \\
\hline 11 & 22,178 & 0,005 & 0,011 \\
\hline 12 & 25,194 & 0,007 & $-0,062$ \\
\hline 13 & 27,521 & 0,022 & $-0,014$ \\
\hline 14 & 4,760 & 0,016 & 0,022 \\
\hline 15 & 9,454 & 0,019 & 0,214 \\
\hline 16 & 17,136 & 0,006 & $-0,011$ \\
\hline 17 & 20,401 & 0,012 & $-0,102$ \\
\hline 18 & 22,718 & 0,028 & $-0,008$ \\
\hline 19 & 5,026 & 0,003 & 0,436 \\
\hline 20 & 12,691 & $-0,013$ & $-0,008$ \\
\hline 21 & 15,850 & $-0,005$ & $-0,113$ \\
\hline 22 & 18,302 & 0,012 & 0,003 \\
\hline 23 & 8,457 & $-0,009$ & 0,053 \\
\hline 24 & 11,128 & $-0,010$ & $-0,151$ \\
\hline 25 & 13,641 & 0,007 & $-0,151$ \\
\hline 26 & 4,118 & 0,023 & $-0,100$ \\
\hline 27 & 5,925 & 0,038 & 0,048 \\
\hline 28 & 3,030 & 0,022 & 0,135 \\
\hline 29 & 5,187 & $-0,018$ & $-0,002$ \\
\hline 30 & 7,809 & $-0,020$ & $-0,004$ \\
\hline 31 & 13,681 & 0,006 & 0,037 \\
\hline 32 & 19,797 & 0,006 & 0,079 \\
\hline 33 & 3,525 & 0,002 & $-0,156$ \\
\hline 34 & 9,047 & 0,017 & $-0,058$ \\
\hline 35 & 15,513 & 0,022 & $-0,036$ \\
\hline 36 & 5,873 & 0,026 & 0,041 \\
\hline 37 & 12,128 & 0,023 & 0,089 \\
\hline 38 & 6,587 & 0,013 & 0,054 \\
\hline 39 & 4,541 & 0,009 & 0,005 \\
\hline 40 & 6,830 & $-0,004$ & 0,002 \\
\hline 41 & 4,368 & $-0,002$ & $-0,020$ \\
\hline \multicolumn{2}{|r|}{ Mean [m] } & 0,006 & $\mathbf{0 , 0 2 7}$ \\
\hline \multicolumn{2}{|r|}{ St. Dev. [m] } & 0,014 & 0,110 \\
\hline
\end{tabular}

Table 6. Distance residuals

The software of the SLAM based system, ZEB Revo Real Time (RT), allows the adjustment of the acquired rings in a unique solution by using the overlapping parts of the different rings. The same comparison between 3D coordinates and distances, thanks to the re-projection of the radiometry extracted from the photogrammetric and terrestrial laser scanning point clouds, has been done and Tables 7 and 8 show the obtained results after the re-adjustments of the MMS rings (MMS2).

By comparing the simple statistical parameters (e.g. means and standard deviations) of the obtained residuals in the two different adjustments of the MMS data it is possible to observe that in the final situation the accuracy of MMS data reaches a standard deviation of about $2 \mathrm{~cm}$ if compared with photogrammetric data.

\begin{tabular}{|c|c|c|c|c|c|c|}
\hline \# & \multicolumn{3}{|c|}{ TS } & \multicolumn{3}{|c|}{ MMS2 - TS } \\
\hline & $\mathbf{X}[\mathbf{m}]$ & $\mathbf{Y}[\mathbf{m}]$ & $\mathbf{Z}[\mathbf{m}]$ & $\Delta \mathbf{X}[\mathbf{m}]$ & $\Delta \mathbf{Y}[\mathrm{m}]$ & $\Delta \mathbf{Z}[\mathrm{m}$ \\
\hline 1 & 66,321 & 112,445 & 92,494 & 0,008 & 0,002 & $-0,014$ \\
\hline 2 & 69,154 & 113,965 & 91,214 & $-0,024$ & 0,018 & 0,026 \\
\hline 3 & 68,009 & 119,291 & 91,38 & $-0,010$ & 0,001 & 0,007 \\
\hline 4 & 69,019 & 123,72 & 92,848 & $-0,010$ & $-0,006$ & $-0,002$ \\
\hline 5 & 72,1 & 127,687 & 92,94 & & & 009 \\
\hline 6 & 71,901 & 135,971 & 91,422 & $-0,035$ & 0,023 & $-0,002$ \\
\hline 7 & 74,812 & 138,475 & 92,978 & $-0,042$ & $-0,011$ & 0,002 \\
\hline 8 & 75, & 140,801 & 91 , & & $-0,008$ & 0,001 \\
\hline 9 & 116,126 & 107,756 & 103,178 & $-0,012$ & $-0,020$ & $-0,018$ \\
\hline 10 & 110,296 & 108,522 & 100,203 & & 031 & 0,014 \\
\hline 11 & 104,437 & 109,143 & 100,18 & 03 & $-0,021$ & $-0,007$ \\
\hline 12 & 101, & 109,517 & 98,293 & & $-0,031$ & $-0,042$ \\
\hline 13 & 96,704 & 110,137 & 100,131 & $-0,016$ & $-0,007$ & 0,008 \\
\hline 14 & 85,784 & 151,59 & 98,415 & $-0,029$ & 0,001 & $-0,001$ \\
\hline 15 & 4,945 & 147,204 & & $-0,034$ & 0,041 & 0,008 \\
\hline 16 & 80,795 & 146,994 & 97,851 & 0,009 & 0,031 & 0,006 \\
\hline \multicolumn{4}{|c|}{ Mean [m] } & $-0,015$ & $-0,003$ & $-0,001$ \\
\hline \multicolumn{4}{|c|}{ St. Dev. [m] } & 0,017 & 0,022 & 0,015 \\
\hline
\end{tabular}

Table 7. 3D coordinate residuals after the second adjustment of MMS data

\begin{tabular}{|c|c|c|}
\hline \# & $\mathbf{A D P}[\mathrm{m}]$ & MM2-ADP [m] \\
\hline 1 & 3,473 & $-0,047$ \\
\hline 2 & 7,147 & $-0,017$ \\
\hline 3 & 11,590 & $-0,003$ \\
\hline 4 & 16,295 & $-0,013$ \\
\hline 5 & 24,218 & $-0,006$ \\
\hline 6 & 27,374 & $-0,017$ \\
\hline 7 & 29,785 & $-0,001$ \\
\hline 8 & 5,445 & $-0,015$ \\
\hline 9 & 9,871 & $-0,007$ \\
\hline 10 & 14,113 & $-0,012$ \\
\hline 11 & 22,178 & 0,004 \\
\hline 12 & 25,194 & $-0,011$ \\
\hline 13 & 27,521 & 0,006 \\
\hline 14 & 4,760 & 0,005 \\
\hline 15 & 9,454 & $-0,003$ \\
\hline 16 & 17,136 & 0,008 \\
\hline 17 & 20,401 & $-0,006$ \\
\hline 18 & 22,718 & 0,013 \\
\hline 19 & 5,026 & $-0,006$ \\
\hline 20 & 12,691 & $-0,003$ \\
\hline 21 & 15,850 & $-0,014$ \\
\hline 22 & 18,302 & 0,005 \\
\hline 23 & 8,457 & 0,014 \\
\hline 24 & 11,128 & $-0,004$ \\
\hline 25 & 13,641 & 0,011 \\
\hline 26 & 4,118 & 0,001 \\
\hline 27 & 5,925 & 0,023 \\
\hline 28 & 3,030 & 0,020 \\
\hline 29 & 5,187 & 0,029 \\
\hline 30 & 7,809 & 0,008 \\
\hline 31 & 13,681 & 0,012 \\
\hline 32 & 19,797 & 0,008 \\
\hline 33 & 3,525 & 0,000 \\
\hline 34 & 9,047 & 0,001 \\
\hline 35 & 15,513 & $-0,005$ \\
\hline
\end{tabular}




\begin{tabular}{|c|c|c|}
\hline \# & ADP [m] & MM2-ADP [m] \\
\hline 36 & 5,873 & 0,005 \\
\hline 37 & 12,128 & 0,001 \\
\hline 38 & 6,587 & $-0,012$ \\
\hline 39 & 4,541 & $-0,048$ \\
\hline 40 & 6,830 & $-0,072$ \\
\hline 41 & 4,368 & $-0,047$ \\
\hline \multicolumn{2}{|c|}{ Mean [m] } & $-0,005$ \\
\hline \multicolumn{2}{|c|}{ St. Dev. [m] } & 0,020 \\
\hline
\end{tabular}

Table 8. Distance residuals after the second adjustment of MMS data

\section{CONCLUSIONS}

The results described above, represent a contribution to those already obtained by other authors and may allow us to affirm how the use of MMS is today a reality to be considered with due attention when dealing with the metric survey of a morphologically complex building.

Moreover, we must not forget the different density of the point clouds that systems based on SLAM technology can provide and the limits in some cases still present of the impossibility of acquiring radiometric information together with the geometric information.

The results obtained from this work confirm that the new points acquired with the MMS offer an excellent integration and even a real possibility of replacing data that can also be acquired with other technologies (such as for example Photogrammetry and Terrestrial Laser Scanning).

Realistically it must be considered that accuracies of a few centimetres, such as those obtained in the case described with the MMS, are more than sufficient in any type of documentation.

It is also clear that the correct integration of different techniques in any case and always required a correct design and execution of a control network of sufficient reliability.

The control network must be designed and built in such a way as to ensure the necessary precision requirements throughout the 3D space of the object to be surveyed.

Finally, it should always be emphasized that a 3D metric survey without the necessary documentation describing the procedures used cannot be considered usable for restoration, conservation and management projects. This concept, which is also the basis of the London Charter, must be increasingly considered as an obligation to make the metric survey "transparent" and professional, which constitutes one of the fundamental pillars of the documentation of cultural heritage.

\section{REFERENCES}

Torres, J. A., Hernandez-Lopez, D., Gonzalez-Aguilera, D., \& Hidalgo, M. A. M., 2014: A hybrid measurement approach for archaeological site modelling and monitoring: the case study of Mas D'is, Penàguila. Journal of archaeological science, 50, 475-483.

Giandebiaggi, P., Ghiretti, A., Roncella, R., Vernizzi, C., \& Zerbi, A., 2015: Integrated survey methodologies for the multiscale knowledge of archaeology of architecture: the survey of the amphitheatre in Durrës. SCIRES-IT-SCIentific RESearch and Information Technology, 5(2), 3-14.

Sirmacek, B., Shen, Y., Lindenbergh, R., Zlatanova, S., \&
Diakite, A., 2016: Comparison of Zeb1 and Leica C10 indoor laser scanning point clouds. ISPRS Ann. Photogramm. Remote Sens. Spat. Inf. Sci, 3, 143-149.

Torres-Martínez, J. A., Seddaiu, M., Rodríguez-Gonzálvez, P., Hernández-López, D., \& González-Aguilera, D., 2016: A multidata source and multi-sensor approach for the 3D reconstruction and web visualization of a complex archaelogical site: The case study of “Tolmo De Minateda". Remote Sensing, 8(7), 550.

Cefalu, A., Haala, N., Schmohl, S., Neumann, I., \& Genz, T., 2017: A mobile multi-sensor platform for building reconstruction integrating terrestrial and autonomous UAVbased close range data acquisition. International Archives of the Photogrammetry, Remote Sensing and Spatial Information Sciences-ISPRS Archives 42 (2017), Nr. 2W6, 42(2W6), 63-70.

Chiabrando, F., Sammartano, G., \& Spanò, A., 2017: A comparison among different optimization levels in 3D multisensor models. A test case in emergency context: 2016 Italian earthquake. The International Archives of Photogrammetry, Remote Sensing and Spatial Information Sciences, 42, 155.

Masiero, A., Fissore, F., Guarnieri, A., Piragnolo, M., \& Vettore, A., 2017: Comparison of low cost photogrammetric survey with TLS and Leica Pegasus Backpack 3D models. International Archives of the Photogrammetry, Remote Sensing \& Spatial Information Sciences, 42.

Rodríguez-Gonzálvez, P., Jimenez Fernandez-Palacios, B., Muñoz-Nieto, Á. L., Arias-Sanchez, P., \& Gonzalez-Aguilera, D., 2017: Mobile LiDAR system: New possibilities for the documentation and dissemination of large cultural heritage sites. Remote Sensing, 9(3), 189.

Malinverni, E. S., Pierdicca, R., Bozzi, C. A., \& Bartolucci, D., 2018: Evaluating a SLAM-based mobile mapping system: a methodological comparison for 3D heritage scene real-time reconstruction. In 2018 Metrology for Archaeology and Cultural Heritage (MetroArchaeo) 265-270. IEEE.

Murtiyoso, A., Grussenmeyer, P., Suwardhi, D., \& Awalludin, R., 2018: Multi-scale and multi-sensor 3D documentation of heritage complexes in urban areas. ISPRS International Journal of Geo-Information, 7(12), 483.

Sun, Z., \& Zhang, Y., 2018: Using drones and 3D modeling to survey Tibetan architectural heritage: A case study with the multi-door stupa. Sustainability, 10(7), 2259.

Di Luggo, A., Campi, M., Repola, L., Cera, V., Scandurra, S., Pulcrano, M., \& Falcone, M., 2019: Evaluation of historical heritage documentation: reality based survey and derivative models. International Archives of the Photogrammetry, Remote Sensing \& Spatial Information Sciences.

Murtiyoso, A., Grussenmeyer, P., Suwardhi, D., Fadilah, W. A., Permana, H. A., \& Wicaksono, D., 2019: Multi-sensor 3D recording pipeline for the documentation of javanese temples. International Archives of the Photogrammetry, Remote Sensing \& Spatial Information Sciences.

Nespeca, R., 2019: Towards a 3D digital model for management and fruition of Ducal Palace at Urbino. An integrated survey with mobile mapping. SCIRES-IT-SCIentific RESearch and Information Technology, 8(2), 1-14. 
Patrucco, G., Rinaudo, F., \& Spreafico, A., 2019: Multi-source approaches for complex architecture documentation: the "Palazzo Ducale" in Gubbio (Perugia, Italy). International Archives of the Photogrammetry, Remote Sensing \& Spatial Information Sciences.

Russhakim, N. A. S., Ariff, M. F. M., Majid, Z., Idris, K. M., Darwin, N., Abbas, M. A., ... \& Yusoff, A. R., 2019: The suitability of terrestrial laser scanning for building survey and mapping applications. International Archives of the Photogrammetry, Remote Sensing \& Spatial Information Sciences.

Rabbia, A., Sammartano, G., \& Spanò, A., 2020: Fostering Etruscan heritage with effective integration of UAV, TLS and SLAM-based methods. 2020 IMEKO TC-4 International Conference on Metrology for Archaeology and Cultural Heritage, 322-327. 